\title{
Recreating Tone in Two Arabic Translations of Landay Poetry
}

https://doi.org/10.33806/ijaes2000.19.2.12

\author{
Hanan Al-Jabri \\ The University of Jordan, Jordan
}

\begin{abstract}
Tone is the way the author expresses an attitude toward the subject. Tone often poses a challenge for translators. The present study is comparative as it explored two Arabic translations of the same Afghan Women's Poetry (landay). The first translation was done by Jamil Salah in 2002 from the French collection Le suicide et le chant, and the second by Abdallah Abushmaes in 2018 from the English Songs of Love and War: Afghan Women's Poetry. The study aimed at identifying the strategies employed by the two translators to convey the tone expressed in landay poems, and determining their effectiveness in transferring it into Arabic. The study shows that the two translators adopted different strategies at the word and structure levels which in some cases overlooked the significance of tone, while in other cases they seemed to recreate a similar tone.
\end{abstract}

Keywords: landay, literature, poetry, tone, translation

\section{Introduction}

Translation of literary texts has been deemed by many scholars the most difficult type of translation. Rhetorical devices and aesthetic features seem to create a new level of challenge for translators who try to transfer the content as well as the form and style of the literary piece. The challenge of rendering a literary piece from one language to another perhaps increases when the translator works on poetry. Factors such as figures of speech, tone, poetry style and form, rhythm, and rhyme come into play. One of the types of poetry is probably landay poetry which is often an oral and anonymous scrap of song created by and for mostly illiterate Afghani people. Traditionally, landays are sung aloud, often to the beat of a hand drum. A landay has only a few formal properties. Each has twenty-two syllables: nine in the first line, thirteen in the second. The poem ends with the sound "ma" or "na" Sometimes they rhyme, but more often not (Poetry Foundation 2013).

Perhaps factors which include precise number of lines and syllables, the 
unknown authors, the concentrated sentiments in such short songs, and the brave themes most songs involve would make translating them even more challenging. Each song of landay involves distinctive feelings of love, separation, war, peace, sorrow, homeland, grief and joy.

\section{Translation of poetry}

The issue of the translatability of poetry has always sparked controversy among scholars. Some of them believe that poetry is lost in translation as Robert Frost stated that "poetry is what gets lost in translation" (Schub 2003: 81), while others believe form is. However, a third camp believes that poetry can be translated if both meaning and styled are maintained in the target text.

Whether the translator pays more regard to one of these aspects over the other, it can be said that literary translation, among all other types of translation, according to Shunnaq and Alta'ani (2013: 187), may be the most difficult type which involves many constraints. Yousef (2012: 49) highlights some of these constraints such as context, grammatical and syntactic rules of source and target languages, conventions of writing, and figurative language. Perhaps such constraints are more evident, according to Shunnaq (1993) and Boase-Beier (2011) when the two languages involved belong to two different linguistic and cultural systems such as English and Arabic.

This long debate is probably attributed to the fact that poetry, according to Connolly (1998:171) "represents writing in its most compact, condensed and heightened form in which the language is predominantly connotational rather than denotational and in which content and form are inseparably linked." Connolly continues explaining the special nature of poetry where the emotive meaning intended by the poet to evoke the emotions of the readers or listeners constitute another level of difficulty. He explains that "Poetry does not only function in terms of semantic content and aesthetic form, it is intended to arouse sentiment and to produce emotional effect. This pragmatic dimension of a poem is perhaps the most difficult to account for in translation" Connolly (1998:174). In the same vein, Mahasneh (2016) points to the complex nature of poetry which combines elements beyond the linguistic surface of words, such as the poet's own emotions, experiences, opinions, musicality and styles. Therefore, she maintains that "poetry would be the most challenging among all branches of literature to be translated" (Mahasneh 2016: 7).

On the level of language, Ravindran (1982:83) maintains that poetic 
language "does not seek to describe reality, but to recreate it - it deals more directly with man's immediate lived experience in the world and thus "opens new possibilities for him." Therefore, the language of poetry dives beyond the surface linguistic meanings of words into reflecting the feelings of the poet. Sartre (1988: 49) argues that the language of poetry reflects the poet's feelings of taste, touch and smell in what they write. Poets tend to employ figurative language to stir special feelings and responses in their readers. It is thus safe to conclude that the translation of poetry, as Newmark (1988: 162) maintains, is "the most testing type of translation."

Due to the unique nature of poetry, some scholars, such as Rose (1981:136) and Raffel (2010: vii) suggest that the translator of poetry must be a poet himself. They stress that the translator must possess good knowledge of both source and target languages, source and target culture and poetry conventions. Translators of poetry, according to them, should be able to go deep in the original text to be in line with the original poet on all levels and to be able to reflect these levels in his/her own language. In the same vein, Shiyab and Lynch (2006: 264) believe poetry can be translated if the translator possesses the theoretical information, sensible abilities, and the capability to cautiously understand the "tone" and "spirit" of the original text.

\section{Tone}

As discussed earlier, the translation of poetry involves many challenges and constraints due to the complex factors involved in poetry. One of these factors which is the focus of this paper is the tone of the speaker of the poem. Tone, according to Claassen (1992:98), can be defined as the effect upon the sensibilities of the reader of the prevailing attitude of mind of the speaker. An author may be serious, humorous, sarcastic, playful, angry and so forth. The tone may remain constant, or it may vary in degree of intensity, or shift entirely at some point in the piece of writing. Claassen emphasises that words in context, sound and rhythm can be employed by the author to create different types of tones. Other devices, such as imagery and simile, were also mentioned by Kirszner and Mandell (2002: 751) as effective in evoking the feelings of the reader. If used efficiently, tone, according to Kirszner and Mandell (2002: 751), will bind the poem with an emotional theme.

The translator, therefore, needs to be able to interpret the tone of the speaker so that he/she reflects that in his/her own language. To be able to do so, he/she 
should be able to analyse the text, identify the different tools used by the poet to create the tone, and then use tools from the target language to reproduce that tone.

\section{Aim of the study}

The paper will examine two Arabic translations of Afghani Poetry (landay). The Landy as were originally sung in Pashto mainly by anonymous Afghani women. Then they were gathered and documented by the Afghani poet and writer Sayd Bahodine Majrouh, and later were translated into French and English, Le suicide et le chant and Songs of Love and War: Afghan Women's Poetry respectively. The paper will use the English translations as source texts. The target texts, on the other hand, will be the Arabic translations made by Jamil Salah, a literary translator, in 2002 from the French collection, and the second by Abdallah Abushmaes, a Jordanian poet, in 2018 from the English one. The study aimed at identifying the strategies employed by the two translators to convey the tone expressed in landay poems, and determining their effectiveness in transferring it into Arabic. The study will examine two kinds of tone: the sarcastic, and the seductive.

\section{Analysis}

The paper will adopt a descriptive approach when analysing the translators' practices and strategies. Then a comparative approach will be used to highlight the possible differences in the rendition of tone between both translations against the English version, on the one hand, and between the Arabic translations themselves, on the other. Moreover, the researcher will evaluate the effect of the Arabic translations of tone to determine whether the tone in the source texts was preserved, toned down, or enhanced. The analysis will embark on two main sections based on two main tones that were observed in the corpus. These sections are the sarcastic tone, and the seductive tone. Each section will include more than one example which illustrate the tone in question along with the Arabic translation of Salah (Translator 1), and the Arabic translation of Abushmaes (Translator 2). Also, back translation (BT) of each Arabic translation will be provided below each translation.

It is important to note that the aforementioned two Arabic translations were made based on translations of the original text, in Pashto, because both Arab translators do not master the Pashto. In other words, the English translations were treated as the source texts. Therefore, this paper aims to compare the tone in the 
Arabic translations against that in the English translation. The Pashto text, in this regard, is beyond the scope of the research because it is almost impossible to for anyone to be certain of the accuracy of the translated poems into English and French $^{1}$

Following each example, a brief analysis of the English text will be provided to give a wider context of the poem and to explain its tone and the possible tools which contribute to creating it. Then, the two Arabic translations will be examined and compared to highlight the tools used by the translators to reflect the intended tone and how effective they were in doing so. The first section is allocated to the first type of tone which is the sarcastic tone.

\subsection{Sarcastic tone}

This tone was mainly found in the poems where the Afghani female poet ridiculed her husband. As most poems show, the Afghani woman used to resent her marriage which was mainly imposed on her by her family. Her husband is either too old or too young which in both cases means he is an inadequate husband. Moreover, her husband, according to the poems, seems to underestimate her. This can be noticed in the following example.

\section{Example 1}

\begin{tabular}{|c|c|c|}
\hline English & Translator 1 & Translator 2 \\
\hline My love, jump into & يا حبيبي، اهبط على فر اشي، لا & اقفز حبيبي! \\
\hline bed with me and & تخش شيئًاً & سرير الثوق ينتظرُ \\
\hline do not fear, & إذا انكسر ، ((البشع الدميم)) هنا & لا تخش شيئًاً إذا مالت بنا السرر \\
\hline If it should break & 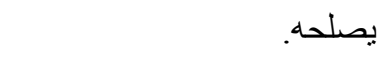 & و إن تكسّر من أضلاعها خشبٌ \\
\hline the "little horror" & (P.16) & فسوف يصلحُهُ هذا ((الفتى القذرُ)) \\
\hline is there for the & & (P.25) \\
\hline
\end{tabular}

\footnotetext{
${ }^{1}$ An anonymous reviewer of IJAES suggested that it is almost impossible to establish the accuracy of a translation of a translation; no-one can be certain of the accuracy of the translated poems into English, nor can anyone determine the precision with which tone was conveyed or how much was added or went missing from the tone of the original text. The current study does not claim that the translations are a faithful recreation of the original as the author does not have access to the original poems; therefore, it aims to address the tone of the translation. The original Pashto text, therefore, is beyond the scope of this study.
} 


\begin{tabular}{|l|l|l|}
\hline repair. (p. 4) & $\begin{array}{l}\text { BT: Oh my love, land on } \\
\text { my bed, do not fear if it } \\
\text { breaks, ((the ugly hideous)) } \\
\text { here will fix it. }\end{array}$ & $\begin{array}{l}\text { BT: Jump my love! } \\
\text { The bed of yearning is } \\
\text { waiting } \\
\text { Do not fear if beds shake us } \\
\text { And if its wooden ribs break } \\
\text { This ((filthy boy)) will fix } \\
\text { them }\end{array}$ \\
\hline
\end{tabular}

In this example, the female poet ridicules her husband by flirting with her lover. She invites him to make love to her on her marital bed and if the bed breaks due to their violent love making, her husband, whom she describes as (little horror), will repair it. The main tool of creating such sarcastic tone is perhaps the image of the husband repairing his marital bed after his wife cheated on him on it.

Looking at the first translation, it can be noticed that word for word translation seems to be adopted although the meaning is reflected. In terms of diction, Translator 1 opted for the collocation اهبط على فراشي (land on my bed), which is very unlikely to be used in Arabic. In fact, the word (jump) is a more natural verb which collocates well with فراشي (bed). It is also a more lively verb which fits quite well with the image of breaking the bed due to jumping into it. Moreover, Translator 1 seems to follow the word order of the original text. This literal translation seems to lead to more distance from the spirit of the original text leading to mitigating the original tone.

On the other hand, Translator 2 seems to opt for a more free translation. For example, he added the phrase سرير الثوق ينتظر (the bed of yearning is waiting) which does not exist in the original text. This addition in fact intensifies the image and creates more contrast between the lucky lover who gets to make love and the ridiculed husband, whose job is only repairing the broken bed. In addition to that, the translator chose words which have negative connotations such as الفتى (boy) which when used to refer to a man is considered an insult. Moreover, the translator, probably due to being a poet himself, maintains rhyme and follows meter which, according to Gill (1985: 50), creates a sense of pleasure due to the harmony between words. Thus, maintaining meter, which is highly valued in Arabic poetry, can beautify the poem and intensify the emotional effect.

\section{Discussion}

Based on the analysis above, it can be argued that Translator 1 seems more keen 
on following the structure and word order of the original text. This strategy of literal translation seems to contribute to creating unnatural structures in Arabic which tone down the effect of the intended tone. Also, the word choice made by the translator was another factor that mitigated this effect. Translator 2, on the other hand, opted for a more elaborate translation by using addition. He also used more natural collocations which helped recreating the original tone in his translation. Finally, following the conventions of Arabic poetry including rhyme and meter contribute greatly to enhancing the intended tone. To conclude, unusual collocations and word for word translation seem to have mitigated the tone in the first translation, whereas applying addition, maintaining rhyme, and using more natural collocations seem to have intensified the tone in the second.

\section{Example 2}

In the following example, the poet continues her harsh criticism of her husband by ridiculing his ability to make love or go to war insulting his manhood. Her husband is simply useless.

\begin{tabular}{|c|c|c|}
\hline English & Translator 1 & Translator 2 \\
\hline $\begin{array}{l}\text { The "little horror" } \\
\text { does nothing- does } \\
\text { not make love, } \\
\text { does not make war. } \\
\text { At night, no sooner is } \\
\text { his belly full, he } \\
\text { climbs in bed } \\
\text { and snores until the } \\
\text { dawn. (p.45) }\end{array}$ & 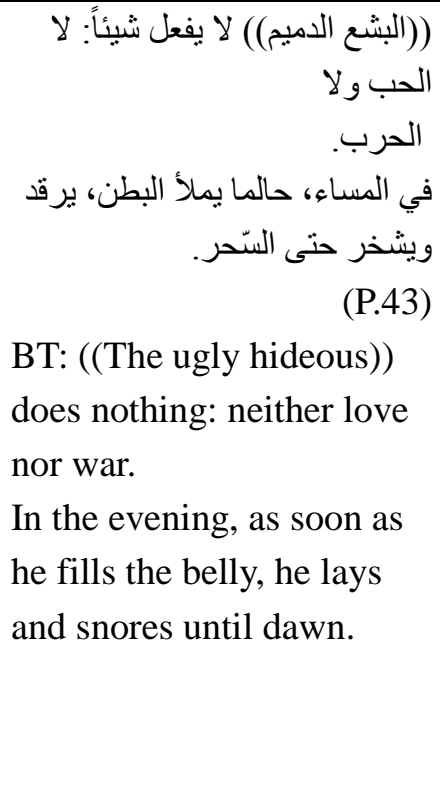 & 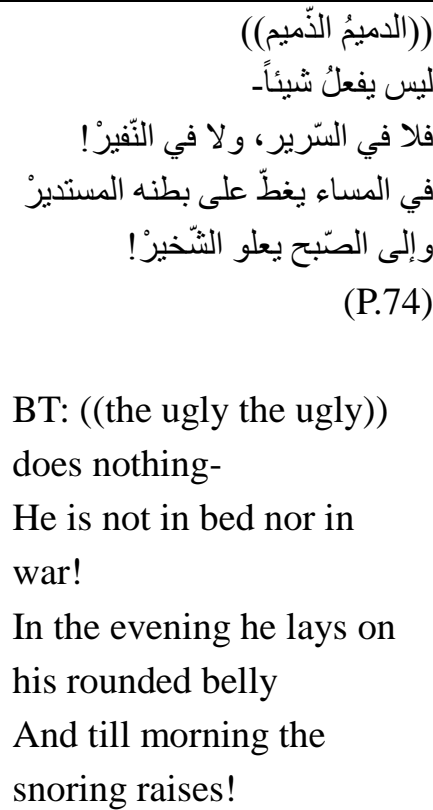 \\
\hline
\end{tabular}


The female poet, once again, uses "little horror" to refer to her useless husband. He is inadequate in bed and in the battlefield. She uses words such as belly, snores and climbs in bed to describe his laziness and passion to just eat and sleep. This image of the lazy husband who has poor love making skills and who is apparently a coward can be traced in both translations. However, Translator 1 seems to adopt literal translation. The phrase لا الحب ولا الحرب (neither love nor war)although has sound effects due to the very similar letters in both words, appears unnatural due to omission of the verb does not make.

In contrast to this, Translator 2 relied on the Arabic proverb لا في العير ولا في النفير (useless in trade and war), replacing the word العير (trade) with the rhyming word السرير bed where bed stands for making love and نفير (going to war) for making war. Both words rhyme as well which increases the effect they produce. Also, using words such as بطنه المستديرlays which rounded belly and associate with laziness contribute to recreating the sarcastic tone.

\section{Discussion}

The careful choice of diction, as the discussion above suggests, along with the effective employment of the Arabic culture seem to contribute to maintaining the original tone of this poem in the translation of Translator 2. On the other hand, literal translation, which led Translator 1 to using ellipsis seems to affect the overall process of conveying the original tone. In short, both translators opted for a diction that reflected the negative image of the husband. However, employing culture and rhyme, in the second translation, seems to have enhanced the effect of the tone over that in the first translation.

\section{Example 3}

\begin{tabular}{|c|c|c|}
\hline English & Translator 1 & Translator 2 \\
\hline $\begin{array}{l}\text { Go away then, my } \\
\text { friend, and travel } \\
\text { well! } \\
\text { You were but one of } \\
\text { my lovers and I'll find } \\
\text { a hundred more. } \\
(p .60)\end{array}$ & 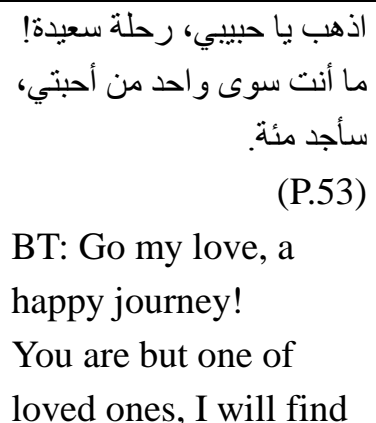 & 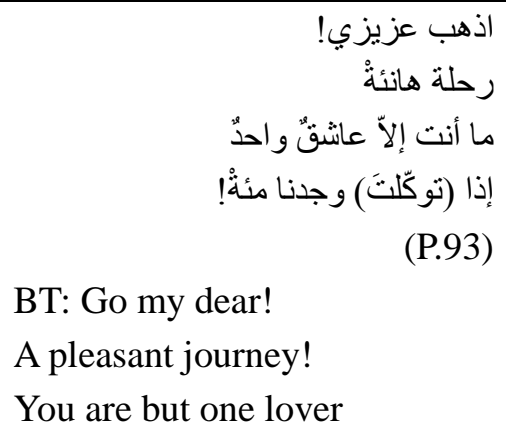 \\
\hline
\end{tabular}




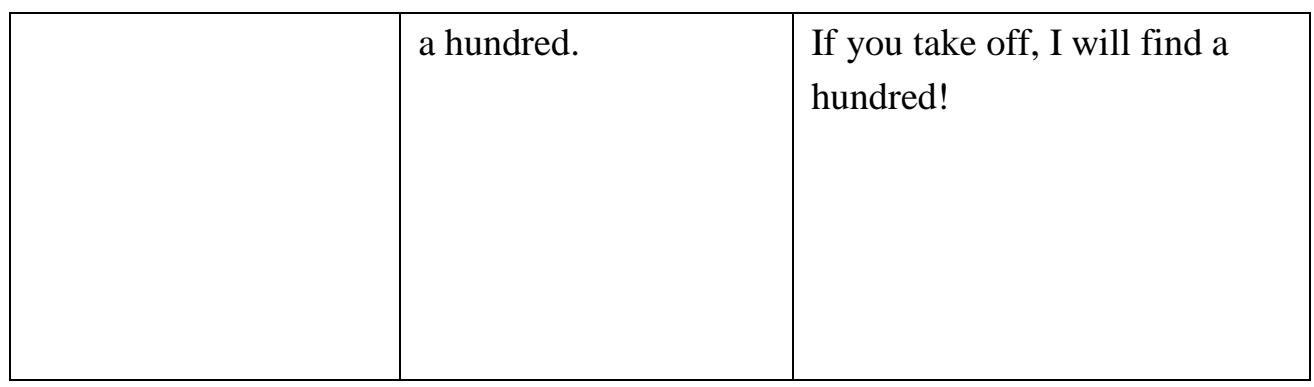

Just as she ridiculed her useless husband, she also targeted her coward lover using sarcasm. In the above poem, for instance, the female poet used this tone to show that she would not care if her lover decided to desert her because many other lovers would seek her love. The tone is probably triggered by the defying nature of the poet. If her lover decides to leave her, she has no problem. She even wishes him a pleasant journey away from her because she will be able to find a hundred more interested lovers. Looking at the first translation, it can be noticed that the tone is quite vague. This is probably due to the diction the translator used. For example, the word lovers was rendered into أحبتي (my loved ones) which refers to family and friends but never indicates the type of love intended by the poet. This turns the poem into an innocent goodbye note. Moreover, the translator, similar to the previous example, used ellipsis in the final line where he deleted the important phrase if you leave me or any other phrase which delivers this sense. This deletion is probably attributed to the literal translation adopted by the translator as the original text does not have this phrase at the end. However, English uses ellipsis as a rhetorical device which is not the case in Arabic as it left the Arabic text vague.

The second translation, on the other hand, demonstrates a different set of diction. Words such as رحلة هانئة/ عزيزي (my dear/ a pleasant journey) along with the colloquial word نوكلت (take off) create a light sarcastic tone which corresponds with the original. Also, the sound effect resulting from the rhyming endings of هانئة (pleasant) and مئة (hundred) intensifies the tone.

\section{Discussion}

Based on the analysis above, Translator 1 leans more towards literal translation which does not help recreate the original tone. Deletion can also be seen in more than one example so far which resulted in changing the original tone. On the other hand, the careful choice of adjectives along with colloquial words seem to have contributed to maintaining the original tone. Sound effects are also a very 
important source of effect which builds up the tone in the second translation.

\subsection{Seductive tone}

Seducing her lover into a taboo relationship is one of the most dominant tones that can be detected in the landay poetry of female poets. Normally, the Afghani woman is the one who initiates and ends the relationship. She is the fearless brave lover and (he) is the coward one. This is why she invites her lover to be as brave as she is. This tone can be found in the following example.

\section{Example 1}

\begin{tabular}{|c|c|c|}
\hline English & Translator 1 & Translator 2 \\
\hline $\begin{array}{l}\text { Come quickly, my love, } \\
\text { so I can give you my } \\
\text { mouth! } \\
\text { Last night I saw you in } \\
\text { my dream, you were } \\
\text { dead and I went mad. } \\
(p .31)\end{array}$ & 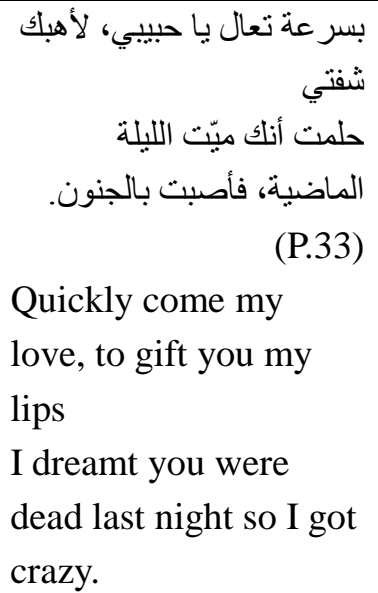 & 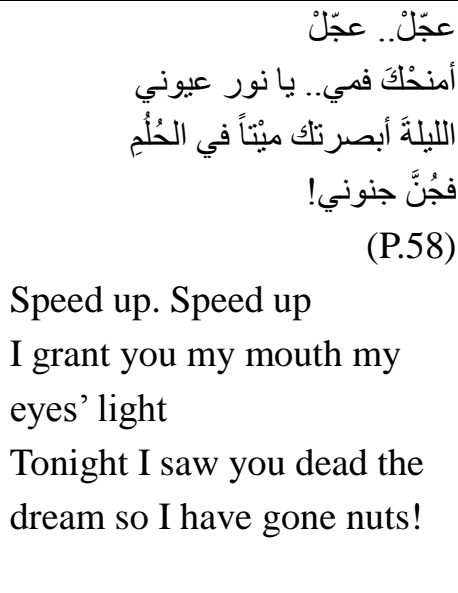 \\
\hline
\end{tabular}

The poet here is asking her lover to seize the moment before it is too late. She is willing to offer him love right now as she is racing with death, which is probably a symbol of everything defying her relationship with him. A quick look at the translations can reveal again the two distinct approaches of the translations adopted by the two translators. Literal translation is reflected in the phrase بسر عة تعال يا حبيبي (quickly come my love) which is more prose than poetry. However, the repetition of the short imperative verb عجّل (speed up), in the second translation, along with the rhythmic and rhyming lines, create the effect of the instant invitation which cannot be delayed. Shamaa (1978: 91) argues that Arabs like to hear repetitive rhythmic patterns probably because the morphological and syntactic system of Arabic imposes certain repetitive patterns which necessarily create rhythmic sound patterns. 


\section{Discussion}

As the case in previous examples, literal translation is the dominant approach that can be found in the first translation. Words which lack poetic effect were used a lot in this translation which toned down the tone in question. On the other hand, the musical effect along with repetition which reflect the approach of Translator 2 seem to work well in recreating the original tone.

\section{Example 2}

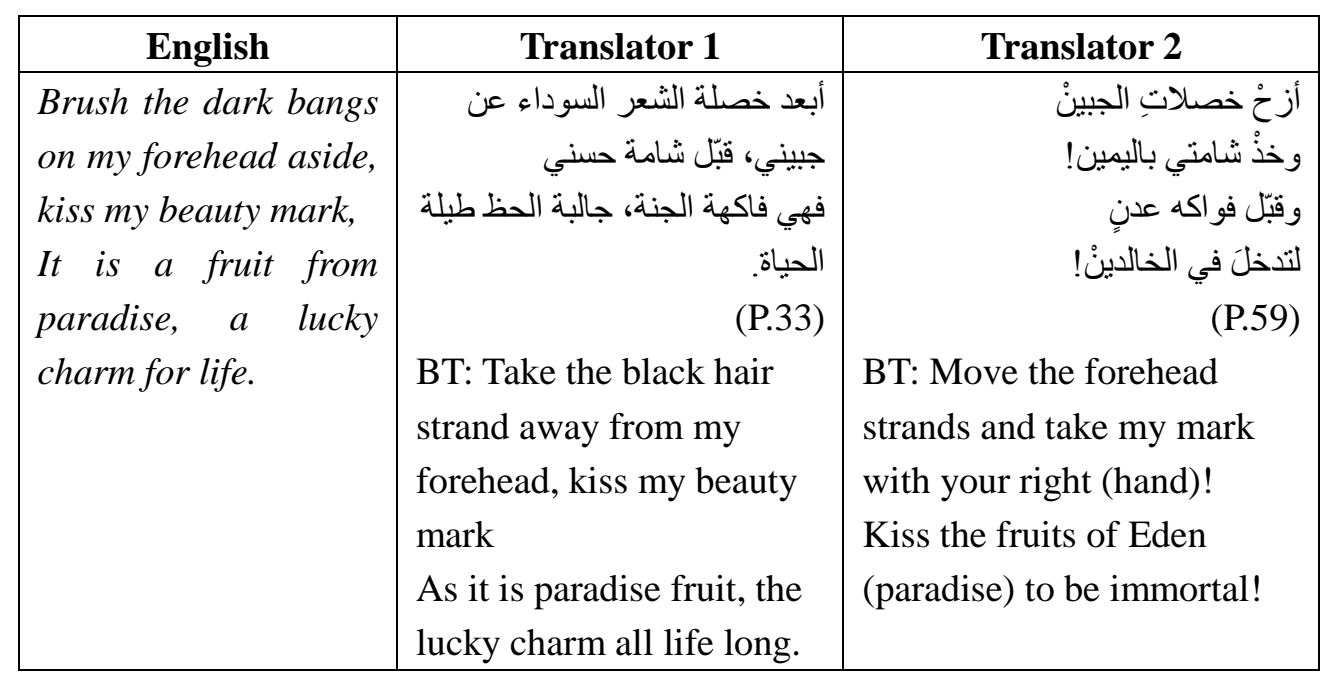

This is another example of the bold seductive tone which can be found in many landay poems. Probably the fact that these poems were orally circulated and had no known author made it easier to adopt this wild tone. For example, in this poem the female poet is asking her lover to make love to her and enjoy her fruits which represent her physical beauty. Words such as fruit, paradise and lucky charm are highly symbolic and important in the creation of the seductive tone. Also, the imperative verbs used are equally important. Although these words are used in both translations, Translator 2 resorted to the Islamic culture choosing some religious loaded words such as خذ شامتي باليمين/عند (Eden/ take my mark with the right (hand)). The expression باليمين with the right hand is used in the Islamic culture to refer to true believers who hold the record of their good deeds with their right hands before entering Paradise, which is Eden, and being immortal. Therefore, in this seductive context, the translator turned the love making request into a holy act. 


\section{Discussion}

Emotive words and expressions which were mainly derived from the Islamic culture are quite the main source of recreating the original tone in the second translation. Such expressions appeal to the target audience and can easily carry the original intended tone. Translator 2 also used emotive words and expressions which recreated similar tone in the target language.

\section{Conclusion}

Based on the analysis above, it can be concluded that tone is a challenging aspect when it comes to the translation of poetry. The translator must pay attention to the tools employed by the poet in the original text which together create the specific tone. He/she then must select equivalent tools in the target language which are able to convey similar tone.

Translator 1, as discussed earlier, resorted mainly to literal translation. In many examples, the original tone was either mitigated or changed due to this strategy. The translator's attempts to follow the original structure of the source text was reflected in the deletions and unnatural collocations he chose. These led only to confusing the meaning let alone the intended tone. Moreover, some lexical items used by the translator were not accurate, which resulted in creating a tone different from the intended one.

The approach of Translator 2, on the other hand, seems to head more towards free translation. The translator relied in many examples on the target culture to select highly emotive words and expressions which contributed to reproducing the original tone in the Arabic text and appealed to the emotions of the Arab audiences. He also employed colloquial, as the case in using توكلت (take off) to recreate the intended tone. Although these strategies of addition and elaboration seem successful, they resulted in adding expressions and words that were not expressed by the original poet. Finally, using emotive adjectives which have special connotations such as رحلة هانئة/بطنه المستدير (his rounded belly/ a pleasant journey) played an important role in recreating the original tone.

It can be concluded, thus, that strategies such as word for word translation, omission, and neutral diction, observed particularly in the translations of Translator 1, seem to have contributed to mitigating the tone intended in the source texts. On the other hand, free translation strategies including addition, substitution, and expansion, which were vastly applied by Translation 2 , appear to 
have magnified the intended tone. Perhaps being a poet himself, Translator 2 was more aware of many challenging factors involved in the translation of poetry, especially sound effect which enhanced the rendition of the tone in the Arabic text.

Hanan Al-Jabri

Department of English Language and Literature

University of Jordan

Jordan

hanan_aljabri@outlook.com

\section{References}

Abushmaes, Abdallah and Hanan Al-Jabri. (2018). ?al-la:nda:y min shic $^{c}$ ? al-mar?ah ?al-?afagha:niyyah fi: ?al-hubb wal-harb. [Landay: From the Poetry of Afghani Women in Love and War]. Amman: Dar Azmina.

Boase-Beier, Jean. (2011). A Critical Introduction to Translation Studies. London/New York: Continuum International Publishing Group Ltd.

Claassen, Jo-Marie. (1992). 'Structure, chronology, tone and undertone: An examination of tonal variation in Ovid's exilic poetry'. Akroterion, 37: 98-113.

Connolly, David. (1998). 'Poetry translation'. In Mona Baker (ed.), Routledge Encyclopaedia of Translation Studies, 170-176. New York: Routledge.

Gill, Richard. (1985). Mastering English Literature. London: Macmillan Education Ltd.

Kirszner, Laurie G. and Stephen R. Mandell. (2002). Holt Handbook. Orlando: Harcourt College Publishers.

Mahasneh, Anjad. (2016). 'Arabic language and emotiveness's translation'. 
International Journal of Social Science and Humanity, 6 (4): 269-274.

Majrouh, Sayd Bahodine. (1994). Le Suicide et le chant. Paris: Gallimard

Newmark, Peter. (1988). A Textbook of Translation. Hertfordshire: Prentice Hall.

Poetry Foundation. https://static.poetryfoundation.org/o/media/landays.html (Retrieved on 2nd Feb 2018).

Raffel, Burton. (2010). The Art of Translating Poetry. Pennsylvania: State University Press.

Ravindran, Sankaran. (1982). Structuralism and Deconstruction. Delhi: Ram and Sons.

Rose, Marilyn Gaddis. (1981). Translation Spectrum: Essays in Theory and Practice. Albany: State University of New York Press.

Salah, Jamil. (2002). ?ash-shicr ?ash-shacbi: lin-nisa:? ?al-bashtu:n. [Popular Poetry of Pashto Women]. Beirut: Arab Diffusion Company.

Sartre, Jean-Paul. (1988). What is Literature? Harvard: Harvard University Press.

Schub, Michael B. (2003). 'That which gets lost in translation'. The Middle East Quarterly, X(4): 81-85.

Shamaa, Najah. (1978). A Linguistic Analysis of Some Problems of Arabic to English translation. Oxford: University of Oxford.

Shiyab, Said and Michael S. Lynch. (2006). 'Can literary style be translated?' Babel, 52(3): 262-275.

Shunnaq, Abdallah. (1993). 'Lexical incongruence in Arabic-English translation due to emotiveness in Arabic'. Turjuman, 2(2): 37- 63.

Shunnaq, Abdallah and Firas Alta'ani. (2013). 'Onomatopoeic problems in translating Conrad's The Lagoon into Arabic'. International Journal of Arabic-English Studies, 14: 187-198.

Yousef, Tawfiq. (2012). 'Literary translation: Old and new challenges'. International Journal of Arabic-English Studies, 13: 49-64. 